\title{
Addendum to: Guideline for acute therapy und management of anaphylaxis
}

\section{Addendum to: Allergo J Int 2014;23:96-112 DOI: 10.1007/s40629-014-0009-1}

Since publication of the guidelines "Acute treatment and management of anaphylaxis" occasionally questions regarding the dosages of adrenaline after intra-venous application have been asked.

Especially the recommended concentration of a $1: 10$ dilution of $1 \mathrm{mg}$ Adrenaline in $10 \mathrm{ml} \mathrm{NaCl}$ $0,9 \%$ intravenously was regarded as too high; higher dilutions were proposed.

The guideline committee has discussed this problem intensively and came to the following addendum, which should help to explain the legends of tables 6 and 7:

1. The doses appearing in the tables have to be red with the general text of the guidelines: intravenous application of adrenaline is only recommended when intra-muscular applications have failed; recommended are solutions of $0,1 \mathrm{mg}$ pro $\mathrm{ml}$ under continuous control of cardiovascular parameters and depending upon effect and side-effects. This concentration corresponds to actual recommendations in position papers and guidelines. The dose can be given in single boli with $0,5 \mathrm{ml}(50 \mathrm{mg})$ according to clinical response.

2. If possible from an organisatorial point of view under non-resuscitation conditions lower concentrations with more precise titration can be achieved by a higher dilution; (e.g. $1 \mathrm{mg}$ adrenaline in $100 \mathrm{ml} \mathrm{NaCl} 0,9 \%$, ie a solution of $10 \mathrm{mg}$ pro $\mathrm{ml}$ or even $1 \mathrm{mg}$ adrenaline in $250 \mathrm{ml} \mathrm{NaCl}$ $0,9 \%(4 \mathrm{mg} / \mathrm{ml})-)$ is recommended. This concentration can be applied under continuous control of cardiovascular parameters and depending upon effects and side-effects. Under monitor control a dose of 1 to 10 (or 15) mg per minute in adults is recommended. The dose can be adjusted according to the clinical response and side-effects.

\section{Prof. Dr. Dr. Johannes Ring}

Department Dermatology and Allergology Biederstein Technical University Munich

Christine Kuehne-Center Allergy Research and

Education (CK-CARE)

Biedersteinerstraße 29

80802 Munich, Germany

E-Mail: johannes.ring@|rz.tum.de

\section{Cite this as}

Ring J, Beyer K, Biedermann T, Bircher, A, Duda D, Fischer J, Friedrichs F, Fuchs T, Gieler U, Jakob T, Klimek L, Lange L, Merk HF, Niggemann B, Pfaar O, Przybilla B, Rueff F, Rietschel E, Schnadt S, Seifert S, Sitter H, Varga E-M, Worm M, Brockow K. Addendum to: Guideline for acute therapy und management of anaphylaxis. S2 Guideline of the German Society for Allergology and Clinical Immunology (DGAKI), the Association of German Allergologists (AeDA), the Society of Pediatric Allergy and Environmental Medicine (GPA), the German Academy of Allergology and Environmental Medicine (DAAU), the German Professional Association of Pediatricians (BVKJ), the Austrian Society for Allergology and Immunology (ÖGAI), the Swiss Society for Allergy and Immunology (SGAI), the German Society of Anaesthesiology and Intensive Care Medicine (DGAI), the German Society of Pharmacology (DGP), the German Society for Psychosomatic Medicine (DGPM), the German Working Group of Anaphylaxis Training and Education (AGATE) and the patient organization German Allergy and Asthma Association (DAAB). Allergo J Int 2016; 25: 67 DOI: 10.1007/s40629-016-0101-9
German Version www.springermedizin.de/ allergo-journal 